OPEN ACCESS

Edited by:

Felix Kwabena Donkor, University of South Africa, South Africa

Reviewed by:

Therese Mwatitha Gondwe Independent Researcher, Lilongwe, Malaw

Eric Brako Dompreh,

The University of Tokyo, Japan

*Correspondence:

Tlou D. Raphela

RaphelaTD@ufs.ac.za

Specialty section:

This article was submitted to Land, Livelihoods and Food Security,

a section of the journal

Frontiers in Sustainable Food Systems

Received: 29 March 2021

Accepted: 11 June 2021 Published: 03 September 2021

Citation:

Raphela TD and Pillay N (2021)

Explaining the Effect of Crop-Raiding on Food Security of Subsistence Farmers of KwaZulu Natal, South

\section{Explaining the Effect of Crop-Raiding on Food Security of Subsistence Farmers of KwaZulu Natal, South Africa}

\author{
Tlou D. Raphela ${ }^{1,2 *}$ and Neville Pillay ${ }^{1}$ \\ ${ }^{1}$ School of Animal, Plant and Environmental Sciences, University of the Witwatersrand, Johannesburg, South Africa, \\ ${ }^{2}$ Disaster Management Training and Education Centre for Africa, University of the Free State, Bloemfontein, South Africa
}

Across the globe, crop-raiding has been known to have a significant impact on subsistence farmers livelihoods in developing countries. However, the relationship between crop-raiding and food security of small-scale farmers is not well-studied. We investigated the effects of crop-raiding on homestead food security of a subsistence farming community on the edge of the Hluhluwe Game Reserve in northern KwaZulu-Natal Province, South Africa. We analyzed the relative calories lost to important food security crops (maize, common bean, spinach, and beetroot) damage by crop raiders. In addition, we conducted questionnaire surveys of resident farmers and conservationists of the Hluhluwe Game Reserve to explain the effect of crop-raiding on food security. We firstly assessed how crop loss influenced relative calorie loss as an indicator of food security by comparing relative calorie loss with two predictors of food security: homestead size and contribution of crops to the farmers' food basket. Larger homesteads were more prone to food insecurity as compared to smaller households as they experienced higher calorie loss, especially in terms of maize (Zea mays), the most important food security crop in South Africa. This was because maize contributed the highest $(91-100 \%)$ to the homestead food basket of these farmers. Secondly, we assessed farmers and conservationists' perceptions and opinions on crop-raiding issues. Farmers reported maize as the crop most damaged by crop-raiding animals. Conservationists reported crop-raiding with other major problems in and around the Reserve; this showed that conservationists acknowledge the issue of crop-raiding as a problem for subsistence farming communities abutting protected areas. Both farmers and conservationists reported insects as the most damaging crop raider. Our study suggests that larger homesteads, particularly where maize contributes substantially to homestead food baskets, are more prone to food insecurity in the rural subsistence farming community that we studied. In concordance with many studies, insects were reported as the culprits by both farmers and conservationists. Small, ubiquitous animals, such as insects are reported to cause much crop damage where they occur. The findings of our study suggest that the food security of the studied farmers is threatened by crop-raiding.

Keywords: crop raiding, food security, homestead size, subsistence homesteads, conservationists 


\section{INTRODUCTION}

Crop raiding by wildlife, defined as the action of, or results of, wild animals damaging standing crops by feeding on or trampling on them (Hill, 2018), contributes significantly to food insecurity of subsistence homesteads adjacent to protected areas (de Garine-Wichatitsky et al., 2017; Guerbois and Fritz, 2017; Mukeka et al., 2019). Since subsistence homesteads depend mainly on crops they grow for their daily nutrients (Mapiye et al., 2020), a reduction in food supply could even result in starvation in subsistence homesteads (Vanhaute, 2011). In addition, crop raiding by wildlife is at the center of shaping opinions and perceptions of conservationists and farmers abutting protected areas because the frequency and intensity of such raiding will create either positive or negative opinions and perceptions about wildlife and conservation in general (Abdullah et al., 2019; Siljander et al., 2020). The risk of attacks on people also significantly influences perceptions and attitudes toward crop raiding (Anand et al., 2018; Hill, 2018). Such perceptions are notably focused on large species such as elephants (Loxodonta Africana) and non-human primates, even when incidences of their raiding are rare (Siljander et al., 2020; Kiffner et al., 2021). Importantly, past studies focused on commercial farmers with little attention on subsistence farmers (Anand et al., 2018; Chen et al., 2019).

The success of conserving biodiversity in protected areas, such as game reserves, depends on the opinions and perceptions of stakeholders of wildlife and conservation, especially of local human communities situated around these areas. Protected areas are reported to be cornerstones for biodiversity conservation (MacKinnon et al., 2020) and are a major means of reducing loss of natural flora and fauna (Schulze et al., 2018). The management of protected areas typically falls to conservationists to protect and manage the needs of wildlife (Matseketsa et al., 2019) while also accommodating the protection of communities around these protected areas. One issue that is of concern to conservationists is human-wildlife conflict experienced by farmers alongside protected areas (Gloriose, 2019). For conservation to be successful, issues that drive conflict such as crop raiding around most conservation areas should also be addressed (Wallach et al., 2018). In this regard, conservation efforts often falter because they fail to fully account for the diversity and multiple levels of human-wildlife conflict in conservation plans and actions (Castaldo-Walsh, 2019). Expanding the scientific knowledge of farmers' perception and opinions of crop raiding behavior is important because such behavior tends to affect the livelihoods of people and can lead to retaliation by farmers (Findlay and Hill, 2021).

In Africa, crop raiding by wildlife is a major influence on subsistence farmers' food baskets (Natukunda, 2019). Subsistence farmers' food basket, also called the farmer's basket, is a customized basket of local agricultural products for daily individual consumption, which is put together by a center of coordination and includes crops from a number of local farms (Rahman and Khan, 2019).

While South Africa may be considered as a food secure country (Zantsi and Bester, 2019), large numbers of subsistence farming homesteads within the country might be food insecure (Zantsi and Bester, 2019; Siphesihle and Lelethu, 2020). We aimed to investigate the effects of crop raiding by wildlife on homestead food security of subsistence farming homesteads adjacent to the Hluhluwe Game Reserve in KwaZulu-Natal Province in South Africa. Food security is defined by Alonso et al. (2018) as the state of having reliable access to a sufficient quantity of affordable, nutritious food, and Wharton (2017) defined subsistence farmers as those farmers who own or manages a farm on which they grow crops or raise livestock sufficient only for their own use, without any surplus for trade.

We investigated food security of subsistence farmers by quantifying the level of damage to four crops, beetroot (Beta vulgaris), common bean (Phaseolus vulgaris), maize (Zea mays), and spinach (Spinacia oleracea), which were important food crops to subsistence farming in the area during the study. We first assessed the interaction of factors (crop type and homestead size) known to influence food security (Kaswamila et al., 2007; Bukie et al., 2018) against relative calorie loss due to crop raiding. Traditionally, homestead dietary diversity considers different food groups consumed (Koppmair et al., 2017), and therefore these food groups add diversity in the farmers' diet, for instance maize adds carbohydrates while common beans adds the muchneeded protein in the diet of these farmers since meat could be expensive for most marginalized communities.

We also used two separate semi-structured questionnaires, and asked farmers about their crop raiding experiences in order to assess (1) which wildlife species farmers perceived to be a problem, (2) which crops farmers think are raided by these animals, and (3) the percentage that crops add to the farmers' food basket. To assess the attitudes and opinions of conservationists toward crop raiding, we considered three overarching questions. (1) What issues are a problem in and around the Reserve? (2) Which animals were reported by farmers to raid their crops? (3) Which animal species/type do they consider as most common crop-raiders and are these animals the same as those reported by farmers?

\section{MATERIALS AND METHODS}

\section{Study Area}

The study was conducted at Phindisweni village $\left(28^{\circ} 26^{\prime} \mathrm{S}\right.$; $\left.31^{\circ} 09^{\prime} \mathrm{E}\right)$, a subsistence farming community on the edge of the Hluhluwe Game Reserve $\left(28^{\circ} 00^{\prime} \mathrm{S} ; 31^{\circ} 43^{\prime} \mathrm{E}\right)$. Homesteads within the study area comprised the study population. The village was characterized by homesteads with high levels of poverty (Statistics South Africa, 2016). Approximately 86\% of the community members depended on crop-based agriculture for their subsistence (Statistics South Africa, 2016). The need for reticulated water, sanitation and electricity were the most pressing issues in the community, with only one homestead reported to have electricity in the 2016 community surveys. These subsistence farms were located on mainly hilly terrain. Like most farming communities abutting protected areas in Africa, this community was affected by crop raiding by wildlife historically (Infield, 1986, 1988) as well as during our study. 


\section{Data Collection}

We collected questionnaire data from 60 subsistence farmers; however, we used data collected on 20 subsistence farms because of the 2015/2016 declared drought disaster in South Africa. Our study design needed data from active famers as we had to collect damaged crops.

The data from these 20 farms used for this study were as follows: (1) damaged crops of maize, beetroot, common bean, and spinach; (2) farm attributes (farm size; cultivated area size and farm slopes); (3) questionnaire survey data in 60 active and inactive farming households; and (4) questionnaire survey data from 35 conservationists of the Hluhluwe Game Reserve. The FAO maintains that food security involves proper nutrition for a healthy life. Thus, we selected the three variables that served as proxies for food security, including: (1) number of crops damaged of the four important crop types, maize, beetroot, common bean, and spinach, which was quantified by counting the total number of damaged individual crop samples (i.e., leaves of beetroot and spinach and seeds of maize and common bean) in quadrats placed on 20 sampled farms; (2) calorie loss, estimated from the loss of the whole or part of the food plants collected; and (3) contribution of crop types to the homestead food basket (hereafter crop contribution) for statistical analysis. Crop contribution was measured as percentages in five categories ( $\leq 30 \%$ of food; $31-60 \% ; 61-90 \% ; 91-100 \%$ ). These variables are reported to influence homestead food security of subsistence farmers (Mugambiwa and Tirivangasi, 2017; Sibhatu and Qaim, 2017; Dodd et al., 2020). Homestead size obtained from questionnaire data, divided into two categories: homesteads with 3-5 people (smaller homesteads) and homesteads with 68 people (larger homesteads), were also used as a variable that could influence food security in our study. Indeed, Aidoo et al. (2013) reported household size as one of the determinants of food security in Ghana.

\section{Relative Calorie Loss}

To quantify calorie loss, we used a fully automatic e2k combustion oxygen bomb calorimeter (Parr Instrument Company, USA) to obtain calorific values of the collected crop samples. Using the calorimeter, we bombed the dried damaged food crops of maize, common bean, spinach and beetroot to obtain the calorific values, using protocol adapted from Nurdin et al. (2018). The calorific values in $\mathrm{kJ} / \mathrm{g}$ were recorded and we estimated potential calorie loss by multiplying the calorific values by the proportional level of damage values (obtained by dividing the level of damage for all crops sampled in a farm by the total number of individual crops in a quadrat). For example, the overall potential calorie loss (hereafter Relative calorie loss) for beetroot during the dry season was $862.02 \mathrm{KJ} / \mathrm{g}$, calculated using the proportional level of damage in all farms sampled multiplied by the calorific values obtained in our study, as follows: Relative calorie loss $=$ proportional level of damage* calorific value $(\mathrm{kJ} / \mathrm{g})$, so $0.18^{*} 4789 \mathrm{KJ} / \mathrm{g}=862.02 \mathrm{KJ} / \mathrm{g}$ (Raphela, 2019).

For the sake of this study, farm size details were collected as follows: using a Garmin GPSMap62 handheld device, we recorded the geographical location (GPS coordinates of the farms) and elevation of the central position of each of the farms sampled. The area of each farm and the area cultivated were established by walking the perimeter of each sampled farm and cultivated land separately and calculating the area of each in $\mathrm{m}^{2}$. The distance between each farm and the reserve boundary was determined by a straight-line shortest distance from the center of the farms to the reserve boundary fence using ArcMap (ArcGIS, V10.3, software package, ESRI).

\section{Questionnaire Surveys}

Interviews are the most effective way to obtain detailed individual opinions and perceptions about an issue. Nonetheless, we are aware that interview-based approaches suffer from biases such as the researcher leading the respondent, respondent anticipation to please the researcher, pushing for concise answers (Alonso and Moscoso, 2017), or discrepancies between what people report and what they actually feel or do (Yan et al., 2020). These weaknesses of the interviews were accounted for in the information sheet and consent forms for both farmers and conservationists by clearly stating that the research was for educational purposes and there would be no compensation for participating and that the potential participants were free to withdraw from the study at any time. Interviews were conducted in English and/or IsiZulu (the local language) for conservationists and in IsiZulu only for the farmers and, only if they agreed, did the interview proceed. The purpose of the survey was explained to the potential interviewee. The identity of all respondents remained anonymous during this study as outlined in the conditions of our ethics permit.

We gathered signed consent forms from each respondent to participate in the study before conducting each survey. Permission to collect data was sought from the University of the Witwatersrand Human Ethics Committee (protocol number H15/11/29) and from the Ezemvelo KZN Wildlife permits office (protocol number P27/2015) and verbal permission to collect data from the community was received from the community chief. The purpose of the survey was explained to the chief and the potential interviewees. Each interviewee was informed that sensitive information and personal characteristics would not be included in any reports without their consent. In addition, an information sheet with information about the research details was also read out to the interviewees. The questions were both closed and open-ended and were aimed at extracting the respondent's opinion on crop raiding by wildlife in neighboring subsistence farms. All respondents interviewed were adults over 18 years of age. The questionnaires, adapted from Seoraj-Pillai and Pillay (2017), were administered with the help of two local research assistants from March 2016 to May 2016.

\section{Farmer's Questionnaires}

We administered 60 semi-structured questionnaires to 60 different farmers, However, we only used 20 questionnaires where farmers were active and had important targeted crops for this study for data analysis. We trained the research assistants about the survey protocol, and they were also given color photographs of wildlife in the Hluhluwe Game Reserve with names in English and isiZulu to assist respondents in identifying crop raiding species. We used a stratified sampling approach to sample the farming homestead. We selected every second 
homestead for the interview. The selection of the homesteads was done in such a way that the homesteads were located a maximum of $6 \mathrm{~km}$ from the reserve boundary. A frequency distribution of distances of farms from the reserve boundary generated a bimodal distribution between farms $<3 \mathrm{~km}$ and those $>3 \mathrm{~km}$. We therefore designated farms $1-3 \mathrm{~km}$ of the reserve boundary as near and farms $4-6 \mathrm{~km}$ as further from the reserve. We restricted the survey to one respondent per homestead to avoid pseudoreplication of results. An average of 7 interviews took place per day throughout data collection phase.

\section{Conservationist's Surveys}

Surveys were limited to conservationists in the Hluhluwe Section of the Hluhluwe iMfolozi Park (HiP). We administered 35 semi-structured questionnaires to 35 conservationists. The questionnaire was divided into three sections, including demographic information, perceptions and opinions of crop raiding by wildlife, and interactions of conservationists with neighboring farming communities. The perception and opinion questions considered whether conservationists knew about conflicts in and around the reserve and reports of crop raiding animals by farmers. Respondents who answered "yes" to these questions were asked supplementary questions about the animal species that were reported and also animals they thought raided crops of adjacent farmers. The survey took place over 3 months from March 2016 to May 2016. Questionnaire interviews were administered at the Hluhluwe Game Reserve research center.

\section{Statistical Analysis}

We first analyzed the relationships between Relative calorie loss and several predictors and their interactions (crop type, homestead size, and crop contribution) to assess the link between the interaction of these predictors and food security by running a series of Generalized linear models (GLM) to find the best fit model. These analyses considered between farm variations to assess whether any of the predictors could be considered for food insecurity. The GLMs were run using the $g l m$ function with a Poisson distribution and Logit link function (lme4 package, Bates et al., 2015). The Relative calorie loss was analyzed as a response variable for all GLMs performed. For all models, we included farm size as a covariate to account for the potential farm size effect. We checked the model fit for the variables described above and used the most appropriate model based on the plot of the residuals against the fitted values from each model. For all models, significance was determined using Wald $\left(\chi^{2}\right)$ statistics and $P$-values were generated by running the Anova of the model (Bates et al., 2015). Next, we applied Spearman rank analysis to assess the relationship between number of crops lost and Relative calorie loss to assess potential food insecurity. We further applied a series of separate GLMMs fitted via maximum likelihood with a glmer function and a binomial distribution (reported and not reported answers) to ascertain the farmers' perceptions and opinions on crop raiding. Lastly, we ran Chi-squared tests $\left(\chi^{2}\right)$ of independence to analyze whether there were differences between the conservationists' responses to the opinion and perception questions asked. All graphs were produced using a GGplot2 package from the R software.

\section{RESULTS}

\section{Relative Calorie Loss}

We presented the model with 3-way interaction as it was the best fit with an AIC value of 13,449 as compared to the other models. There were significant differences found for all crop types, crop contribution, the interaction between all crop types and household size, the interaction between all crop types and crop contribution, the interaction between household size and crop contribution and the three-way interaction between crop type-maize, household size and crop contribution (Table 1). However, there was no significant difference between household size, the interaction between crop type common bean and household size, the three-way interaction between crop typecommon bean, household size and crop contribution and the three-way interaction between crop type-spinach, household size and crop contribution (Table 1). Farm size was also a significant predictor of the relative calorie loss (Table $\mathbf{1}$ ).

Significantly higher calorie losses were: (1) in larger homesteads as compared to smaller households; (2) for maize across household size; and (3) in larger households across all crop types, except for spinach, with maize reported as contributing more to larger households' food basket (91-100\%) as compared to other food crops (Figure 1). Common bean was the second food crop with the highest relative calorie loss across the household size with inconsistent reports by farmers about the contribution of common bean to household food basket between the households, but farmers from larger households where Relative calorie loss was calculated to be high for common bean also reported the highest crop contribution of this crop (Figure 1). The Spearman rank correlation showed a negative statistically significant relationship between Relative calorie loss and number of crops lost $\left(\mathrm{r}_{\mathrm{s}}=-0.55 ; P<0.001\right)$.

\section{Farmers and Conservationists' Perceptions About Crop Raiding}

We analyzed farmers, and conservationists' responses to major questions pertinent to this study as detailed below.

\section{Problems in and Around the Reserve}

We asked conservationists whether they knew of any anthropogenic and crop-raiding problems in and around the reserve. Only one conservationist out of 35 did not know of any problems/issues in and around the reserve, which was significantly different to chance $\left(\chi^{2}=31, \mathrm{df}=1, P<0.001\right)$. We further asked which problems/issues they knew about in and around the reserve from a list of possible problems. Of the 34 respondents who reported problems, 15 (41\%) indicated collection of fuelwood by the local communities, 30 (88\%) indicated crop raiding by wildlife and domestic live-stock, 7 (20\%) indicated cutting of trees by the local communities, 31 (91\%) diseases, 13 (38\%) fires and grazing by domestic live-stock, 34 (97\%) hunting by the local communities, 32 (94\%) indicated poaching and 1 (3\%) indicated trespassing (Figure 2).

There were significant differences in the number issues/problems and those that were not reported by conservationists for crop raiding, cutting trees, diseases, hunting, 
TABLE 1 | Output of a GLM model showing crop types damaged, crop contribution, household size and their interactions with farm size as a covariate for relative calorie loss.

\begin{tabular}{|c|c|c|c|c|}
\hline Variables & Estimate & Std. error & Z-value & $P$-value \\
\hline Crop type_beetroot & 2.967 & 0.355 & 8.341 & $P<0.001$ \\
\hline Crop type_common bean & 5.760 & 0.278 & 7.090 & $P<0.001$ \\
\hline Crop type_maize & 6.552 & 0.139 & 46.848 & $P<0.001$ \\
\hline Crop type_spinach & 7.078 & 0.954 & 74.163 & $P<0.001$ \\
\hline Household size & 0.040 & 0.057 & 0.709 & $P=0.478$ \\
\hline Crop contribution & 0.208 & 0.997 & 2.134 & $P=0.032$ \\
\hline Farm size & 0.000 & 0.000 & -6.603 & $P<0.001$ \\
\hline Crop type_common bean: household size & 0.140 & 0.073 & 1.909 & $P=0.056$ \\
\hline Crop type_maize: household size & -0.246 & 0.062 & -3.964 & $P<0.001$ \\
\hline Crop type_spinach: household size & -0.199 & 0.059 & -3.332 & $P<0.000$ \\
\hline Crop type_common bean: crop contribution & 0.769 & 0.121 & 6.329 & $P<0.001$ \\
\hline Crop type_maize: crop contribution & -0.594 & 0.105 & -5.649 & $P<0.001$ \\
\hline Crop type_spinach: crop contribution & -0.386 & 0.101 & -3.825 & $P<0.001$ \\
\hline Household size: crop contribution & -0.413 & 0.016 & -0.256 & $P=0.000$ \\
\hline Crop type_common bean: household size: crop contribution & -0.085 & 0.020 & -4.196 & $P=0.797$ \\
\hline Crop type_maize: household size: crop contribution & 0.072 & 0.017 & 4.162 & $P<0.001$ \\
\hline Crop type_spinach: household size: crop contribution & 0.288 & 0.016 & 1.715 & $P=0.086$ \\
\hline
\end{tabular}

Significant values are shown in bold.

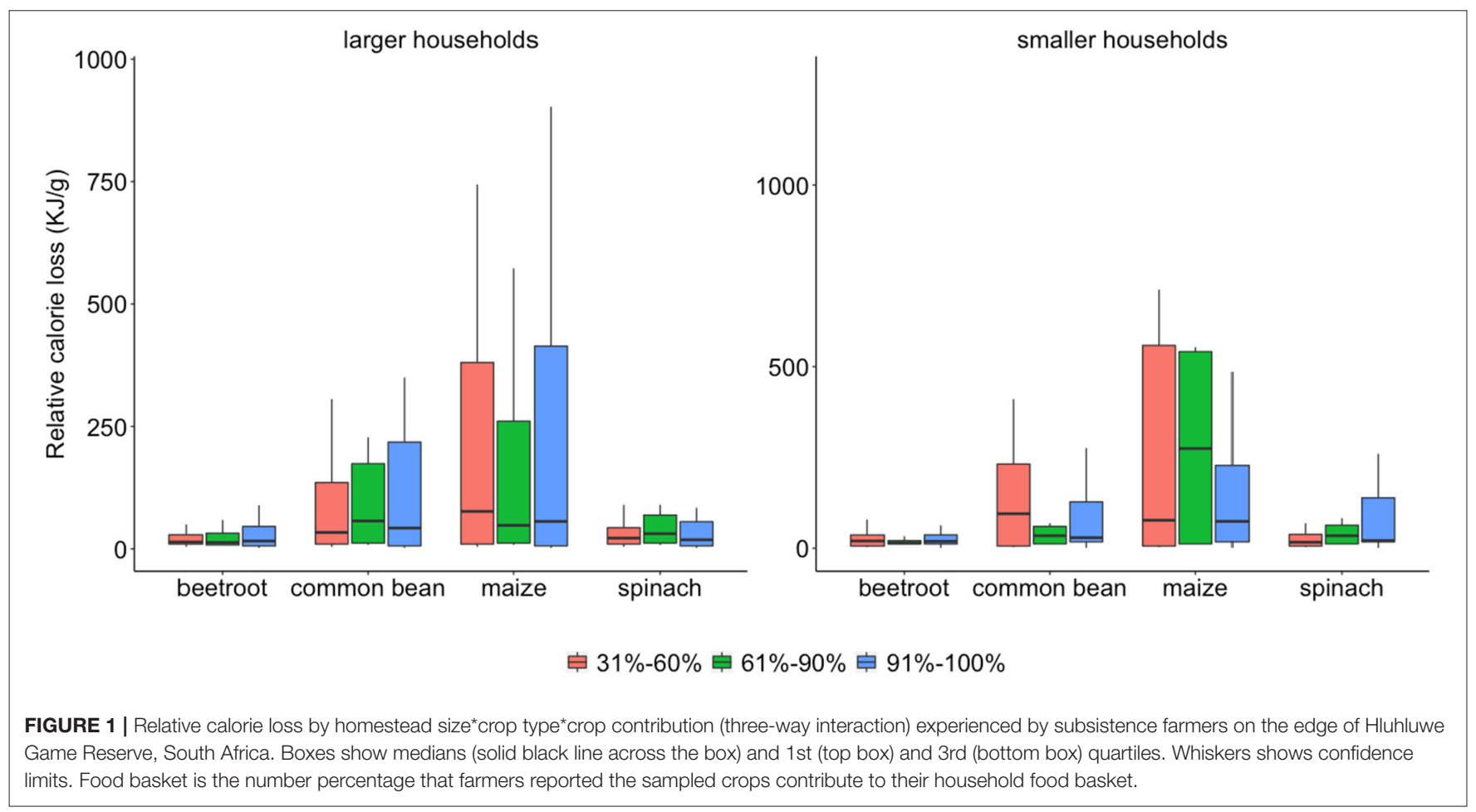

poaching, and trespassing whereas no significant differences were found in conservationists' responses for collection of fuelwood, fires and grazing (Figure 2).

\section{Crop Types Raided}

Farmers near and further away from the reserve reported banana (Musa paradisiaca), beetroot (Beta vulgaris), butternut
(Cucurbita moschata), cabbage (Brassica oleracea var. capitata), common bean (Phaseolus vulgaris), guava (Psidium guajava), maize (Zea mays), mango (Mangifera indica), orange (Citrus aurantium), peach (Prunus persica), potato (Solanum tuberosum), pumpkin (Cucurbita pepo), spinach (Spinacia oleraceae), sweet potato (Ipomoea batatas), and yam (Colocasia esculenta), as crops raided on their farms (Figure 3). 


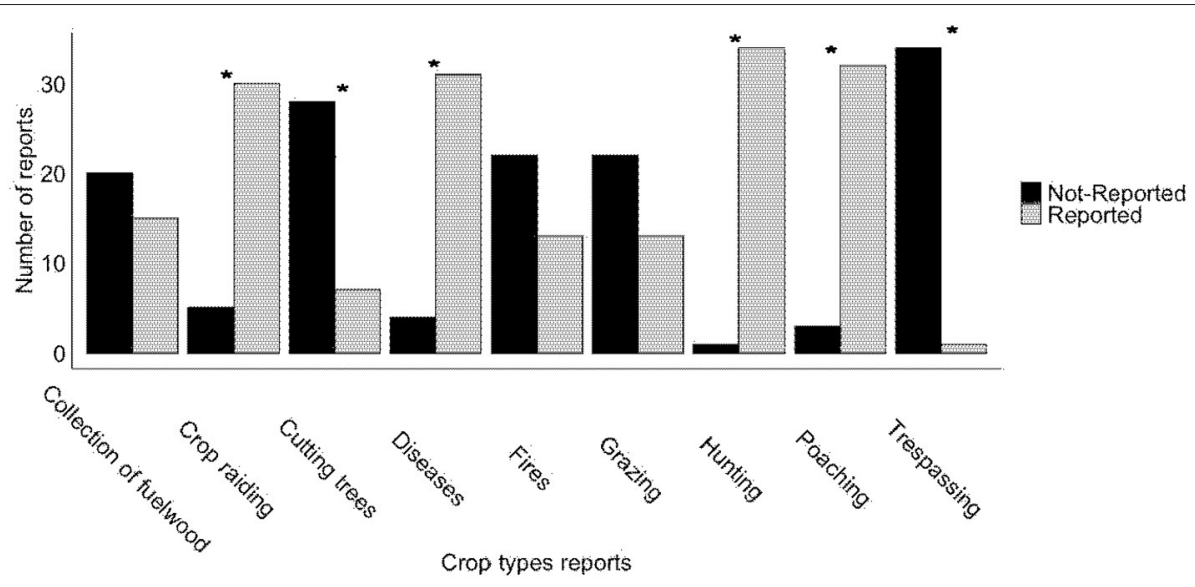

FIGURE 2 | The number of conservationists that did and did not report issues/problems concerning the local farming communities at the edge of the Hluhluwe Game Reserve boundary, South Africa. Asterisks above bars show significant differences between conservationists that reported issue/problem vs. those that did not report those issue/problem.

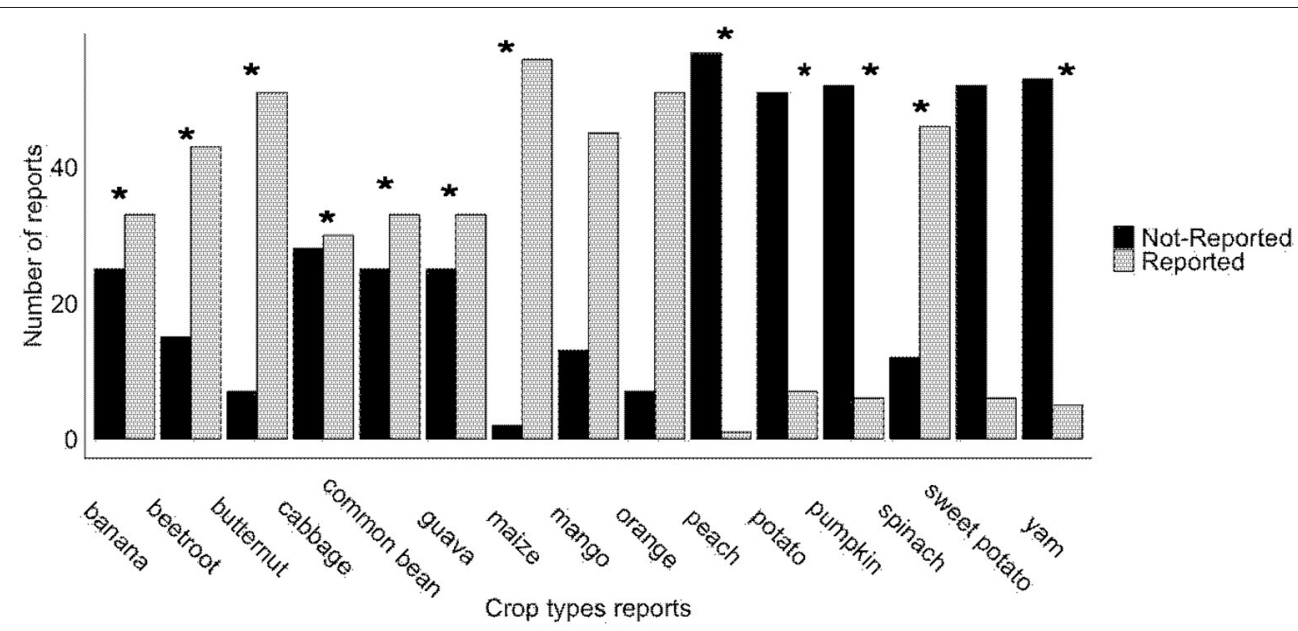

FIGURE 3 | The number of farmers that did and did not report raiding of different crop types at the edge of the Hluhluwe Game Reserve boundary, South Africa. Asterisks above bars show significant difference between farmers that reported a particular crop type was raided vs. those that did not report that crop type.

Crop raiding reports were significantly affected by crop type [Wald $\chi_{(14)}^{2}=105.92, P<0.001$ ] and the interaction between crop type and distance of farms from the reserve [Wald $\chi_{(14)}^{2}$ $=29.26, P=0.009$ ]. Significantly higher number of farmers reported that maize (Zea mays) was mostly damaged compared to all the other crop types and significant differences were found between farmers' responses for banana, beetroot, butternut, cabbage, common bean, guava, maize, peach, potato, pumpkin, spinach, and yam, whereas no significant differences were found between farmers, responses for mango, orange, and sweet potato (Figure 3).

\section{Crop Raiding Animals}

We asked both farmers and conservationists about animals that raid their crops or that they thought raid crops. Farmers mentioned more animals are compared to conservationists
(Figures 4A,B). However, significantly higher numbers of farmers and conservationists reported crop raiding by insects as compared to all other crop raiding animals (Figures $4 \mathrm{~A}, \mathrm{~B}$ ). Reports of crop raiding by farmers were significantly affected by crop raiding animal type [Wald $\chi_{(12)}^{2}=87.76, P<0.001$ ] and the interaction between animal type and farm distance from the reserve [Wald $\chi_{(12)}^{2}=23.13, P=0.026$ ], but there was no significant effect for the farm distance to the reserve boundary [Wald $\chi_{(1)}^{2}=0.36, P=0.544$ ]. Significant differences were found between farmers' responses for all reported animals except for free living birds and vervet monkey (Figure 4A).

In total, 31 of 35 conservationists ( $88 \%$ ) reported crop raiding animals and 4 of the conservationists did not respond to this question and there were significant differences between the responses $\left(\chi^{2}=17 \mathrm{df}=1, P<0.001\right)$. There were significant differences in the number of conservationist's responses for all 

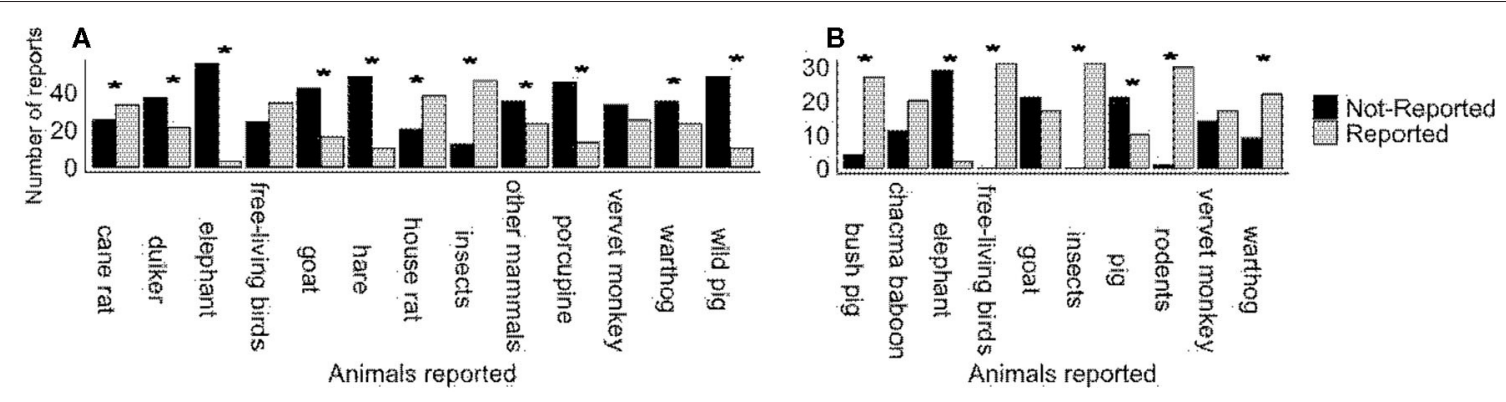

FIGURE 4 | The number of farmers (A) and conservationists (B) that did and did not report crop raiding animals and potential crop raiding animals, respectively, at the edge of the Hluhluwe Game Reserve boundary, South Africa. Asterisks above bars show significant differences between reports of a crop raiding animal type vs. those that did not report that animal type.

animals reported except for chacma baboon (Papio ursinus), domestic goat, and vervet monkey (Figure $4 \mathbf{B}$ ).

To follow-up on crop raiding animals in order to ascertain real and perceived crop raiding animals before linking these animals to exacerbation of food insecurity, conservationists were asked which animals do farmers report as crop raiders. Bush pig (Potamochoerus larvatus), warthog (Phacochoerus africanus), vervet monkey (Chlorocebus pygerythrus) and porcupine (Hystrix africaeaustralis), elephant (Loxodonta africana) were reported by conservationists as culprits similar to farmers reports, even though farmers reported more crop raiding animals than conservationists (Table 2 and Figure 4B). Significant differences were found between farmers, reports for African wild dog (Lycaon pictus), elephant, lion (Panthera leo), vervet monkey, and warthog (Table 2).

\section{DISCUSSION}

Several factors such as food crops, household size, crops contribution to household food basket and crop raiding animals can be linked to household food insecurity of subsistence farmers (Nyirenda et al., 2018; Dodd et al., 2020). In Eastern Zambia, Nyirenda et al. (2018) showed how crop raiding elephants of Lupande Game Management Area affected the food security of the neighboring subsistence farmers. In Hungary, Dodd et al. (2020) reported larger households that do not grow maize and beans to be more likely to experience insufficient food.

Here we investigated how crop raiding by wildlife affects food security of subsistence households adjacent to the Hluhluwe Game Reserve, South Africa. We assessed the perceptions and opinions of farmers on the edge of the Hluhluwe Game Reserve boundary and conservationists employed in different positions by the Reserve on crop raiding issues that could lead to food insecurity.

As a guideline for food security, the World Health Organization (2020) maintained that people's diets must meet the requirements for a healthy life. We investigated the potential calories lost by crop types raided, household size, crops contribution to farmers' food basket, and found that larger households experienced higher relative calorie loss compared to smaller households, particularly for maize. This finding could see these farmers transition from being food secure to being food insecure rapidly. A study in Honduras has shown that larger subsistence farming households, especially those that do not grow maize and beans as their staple foods, are more likely to experience insufficient food compared to individuals from wealthier and smaller households (Dodd et al., 2020). Following the definition of food security by the (Food and Agricultural Organization (FAO), 2010), this finding implies that larger households were more prone to food insecurity compared to smaller households. In many African societies, maize is a preferred food crop because it provides a higher yield for lower input of labor (Silva et al., 2019). Thus, maize is a staple and food security crop in South Africa (Sinyolo, 2020). Maize also provides at least $30 \%$ of the food calories for more than 4.5 billion people in 94 developing countries and contributes to over 20\% of food calories in parts of Africa and Asia [Food and Agricultural Organization (FAO), 2016]. In addition, maize is also a key indicator in the assessment of food security in most developing countries since it is important to the poor as a means of overcoming hunger (Lopez-Ridaura et al., 2019), yet the nutritional value of maize makes it more vulnerable to raiders such as primates (Siljander et al., 2020).

In North-eastern Tanzania, crop raiding by wildlife was reported to have reduced maize yields that could sustain a family up to 11 months per year (Kaswamila et al., 2007). We found that the highest relative calorie loss occurred in households where maize contributed the highest (91-100\%) to the farmers food basket, implying that these households were more prone to food insecurity as compared to households where food crops contribute less to the household food basket.

We also found that farm size was a significant predictor of Relative calorie loss and the number of crops lost predicted Relative calories loss, indicating that potential calorie loss is coupled with crop loss and the size of the farms in our study. The more subsistence farmers in our study lose crops, the more likely they are to become vulnerable to food insecurity because of the relationship between calories lost and the number of crops lost found in our study. Indeed, the size of the farms will also determine food security as subsistence farmers that cultivated a large portion of their farm can have some food crops left after 
TABLE 2 | Results of Chi-squared statistics analysing the responses of conservationists to the question "which animals do communities report to the Reserve as crop raiders?"

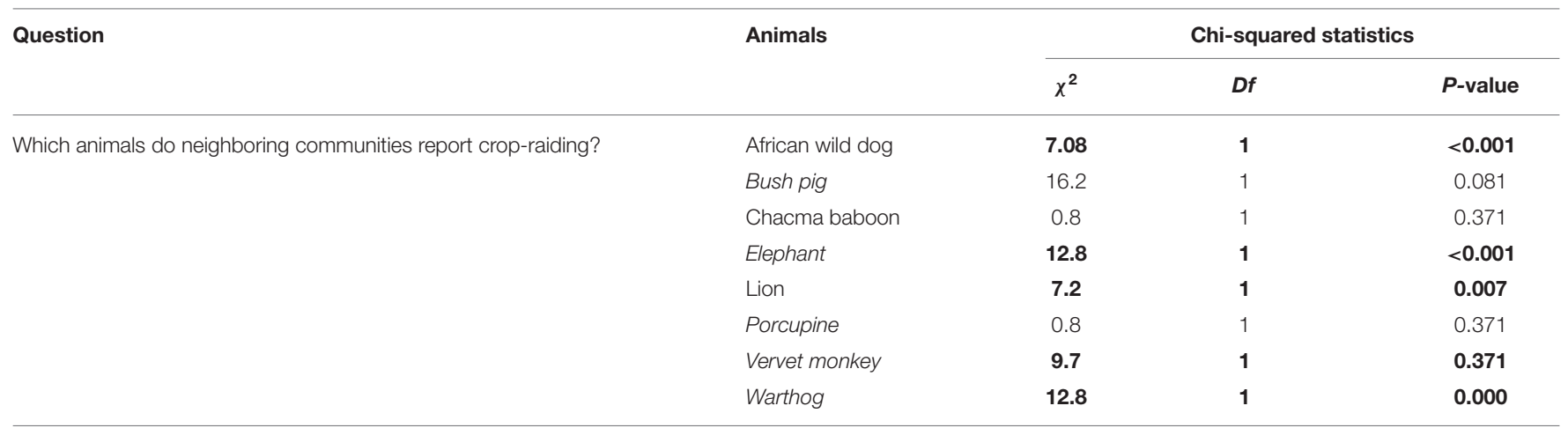

Significant values are shown in bold, and animals reported by both farmers and conservationists are italicised.

extensive raids. This further implies that should crop raiding persist in our study area, the farming homesteads, especially larger homesteads which cultivated smaller areas, will become more susceptible to food insecurity.

Farmers and conservationists reported incidences of crop raiding on the edge of the Hluhluwe Game Reserve boundary. Conservationists did not answer the question of crop types raided, as an important food security predictor (Dodd et al., 2020), but conservationists did confirm that crop raiding is the third highest problem experienced by farmers adjacent to the reserve (See Figure 2). Nevertheless, farmers reported a range of important food security crops being targeted by crop raiding animals (see Figure 3). Consistent with other humanwildlife conflict studies (Adeola et al., 2018; Alemayehu and Tekalign, 2020; Siljander et al., 2020), farmers reported that maize was the most damaged by crop raiding animals. Adeola et al. (2018) found that maize was the most commonly ranked crop of seasonal harvest that was lost to primates raiding around Kainji Lake National Park in Nigeria. In Kenya, Long et al. (2020) found that maize made up 55\% of the cases reported in relation to human-wildlife conflict. Maize is the food crop favored above other crops by people and crop-raiding herbivores and omnivores (Alemayehu and Tekalign, 2020) and most of the studied households rely on subsistence farming as their main livelihood. Therefore, crop-raiding, especially of the most recognized staples, is a serious threat to their food security.

Singh et al. (2017) and Smith et al. (2018) reported that the crops people consider to be vital to their subsistence are also the crops they perceive to be most vulnerable to damage from wild animals. Maize has been identified as a frequently raided crop in many studies (Adeola et al., 2018; Alemayehu and Tekalign, 2020; Long et al., 2020) and our study through experiments and perceptions of farmers and conservationists provides an assessment of the vulnerability of this important food security crop to crop-raiding.

Both farmers and conservationists reported that smaller, more ubiquitous and more persistent animals (i.e. insects and freeliving birds) as the most important crop raiders outside the reserve, but insects were reported by the highest number of farmers and conservationists as the number one crop raider in our study, consistent with other studies in Africa (Yeheyes and Abebaw, 2017; Deutsch et al., 2018). Deutsch et al. (2018) reported insect pests to substantially reduce yields of three staple grains, rice, maize, and wheat, which are also reported food security crops in most African subsistence homesteads. Many studies in Africa reported insects as one of the major problems in agricultural land (Yeheyes and Abebaw, 2017; Deutsch et al., 2018; Okonya et al., 2019) and the damage they cause is always reported as widespread (Dively et al., 2018). However, conflict, drought, and insects have all been leading concerns for African food security in recent years ${ }^{1}$. Worst is that our study took place during the 2015/2016 drought season in South Africa. Therefore, the vulnerability of our study community to food insecurity was escalated during the study. Insects were also reported with other determinants of household food security with annual mean loss of 2687.6 Ethiopian Birr in households in the Omo-nada district in South Western Ethiopia (Yeheyes and Abebaw, 2017). This shows how insects as crop raiders can adversely affects the rural household food security. In Rwanda and Burundi, Okonya et al. (2019) found that insects caused widespread damage to crops, leaving the subsistence farmers vulnerable to food insecurity.

\section{CONCLUSION}

We investigated the impact of crop raiding by wildlife on food security of subsistence farmers on the edge of the Hluhluwe Game Reserve. Our study was the first to consider humanwildlife conflict in marginalized rural communities by directly measuring the impact of wildlife and by soliciting the views and opinions of subsistence farmers and conservationists in South Africa simultaneously. Specifically, we found that insects frequently depredated staple food security crops (maize) and other crops. Moreover, we found that larger homesteads and small farms were more prone to food insecurity because of crop raiding. However, the crop raiding animals and the level of damage recorded would have been unlikely to cause food

${ }^{1}$ Anderson, W., Taylor, C., McDermid, S. P., Ilboudo-Nébié, E., Seager, R., Schlenker, W., et al. (under review). Characterizing the effect of drought, conflict, and locusts on food security in Africa. doi: 10.21203/rs.3.rs-104065/v1. 
insecurity in the studied homesteads. Thus, our study indicates potential but not actual food insecurity because of crop raiding. The food security of the studied farmers during the study was threatened by damage caused by insects coupled with the prevailing drought. The loss of food crops, in particular maize crops, due to crop raiding could exacerbate the farmers plight, leading to food insecurity.

An important finding of our study was consistency between conservationists and farmers on crop raiding animals reported. Conservationists also reported crop raiding was a major problem in and around the Reserve, which showed that they acknowledge the issue of crop raiding as a problem for subsistence farming communities.

\section{Recommendations}

Our study suggests several areas of future research. (1) There is a need for a long-term study of the Phindisweni community to cover many seasons over several years. This will provide an important comparison with the data obtained in our study, which was conducted during a drought. (2) Other proxies of loss of crop raiding, such as crop yield, need to be considered. Although we attempted to quantify nutritional loss of crop parts through their damage, crop yield prior to and after damage was not known because farmers did not keep crop yield information (pre-and post-harvest) during the prevailing drought. Studies around Africa and India have investigated loss based on crop yield (Sekhar, 1998; Mackenzie and Ahabyona, 2012). In India, near the Tiger Reserve, Sekhar (1998) found that the crop yield was $\sim 30-35 \%$ more than when there was no major damage. Around the Kibale National Park in Uganda, Mackenzie and Ahabyona (2012) reported 20\% loss of crops due to crop raiding compared to the crop yield without damage in the previous 6 months. (3) Future investigations should incorporate more detailed nutritional analyses of cultivated foods consumed at different times of the year, and patterns and changes over longer periods of time. Sampling might have to be done opportunistically since crop raiding can be unpredictable, depending on a particular set of environmental conditions (e.g., high rainfall, high crop yields, and ease of accessibility of wildlife to crops). (4) We suggest that prospective studies incorporate a mixture of analytical methods to quantify food security, such as including questionnaire interviews that ask farmers about the food they consumed to quantify food security using dietary diversity. Such methods would be critical in evaluating how food

\section{REFERENCES}

Abdullah, A., Sayuti, A., Hasanuddin, H., Affan, M., and Wilson, G. (2019). People's perceptions of elephant conservation and the human-elephant conflict in Aceh Jaya, Sumatra, Indonesia. Eur. J. Wildl. Res. 65, 1-8. doi: 10.1007/s10344-019-1307-1

Adeola, A. J., Ibrahim, A. O., Adeola, A. N., Alaye, S. A., and Akande, O. A. (2018). Primates associated with crop raiding around borgu sector of Kainji Lake National Park, Nigeria. World News Nat. Sci. 18, 223-231.

Aidoo, R., Mensah, J. O., and Tuffour, T. (2013). Determinants of household food security in the Sekyere-Afram plains district of Ghana. Euro. Sci. J. 9, 34-40. crops contribute to the homestead food basket (Hill, 2000). (5) Although our study has shown that crop raiding is a challenge for the farmers, we do not have data about how they can mitigate against food insecurity should this arise. (6) Finally, we also need studies in other parts of South Africa, especially where subsistence farmers abut protected areas with different environmental conditions, to assess whether our findings are generalizable across South Africa. Most importantly, we strongly recommend that farmers focus more on mitigation strategies that will address crop raiding by insects, free living birds and rodents as they were the most reported crop raiders. Also, maize as the most damaged and raided food security crop, should be given priority when mitigation measures are implemented.

\section{DATA AVAILABILITY STATEMENT}

The raw data supporting the conclusions of this article will be made available by the authors, without undue reservation.

\section{ETHICS STATEMENT}

The studies involving human participants were reviewed and approved by University of the Witwatersrand's' Human (HREC) (non-medical) under protocol number H15/11/29. The participants provided their written informed consent to participate in this study. The animal study was reviewed and approved by University of Witwatersrand Animal Ethics Screening Committee (2015/08/37/B).

\section{AUTHOR CONTRIBUTIONS}

TR and NP conceived and designed the study, research, work, and analyzed the data. TR collected the data and led the drafting of the manuscript. All authors contributed critical, intellectual content to the drafts, and gave final approval of the version to be published.

\section{FUNDING}

This study was supported financially by the National Research Foundation under Grant number (111309) and the University of the Witwatersrand. 
Bukie, J. O., Yager, G. O., and Tsavyange, G. A. (2018). "Wild animal raid on agricultural crops in Katsina-Ala local government area of Benue State, Nigeria," in Proceedings of 6th NSCB Biodiversity Conference (Uyo).

Castaldo-Walsh, C. (2019). Human-Wildlife Conflict and Coexistence in a Morethan-Human World: A Multiple Case Study Exploring the Human-ElephantConservation Nexus in Namibia and Sri Lanka. Fort Lauderdale-Davie, FL: NSUWorks.

Chen, X., Zhang, Q., Peterson, M. N., and Song, C. (2019). Feedback effect of crop raiding in payments for ecosystem services. Ambio 48, 732-740. doi: 10.1007/s13280-018-1105-0

de Garine-Wichatitsky, M., Fritz, H., Chaminuka, P., Caron, A., Guerbois, C., Pfukenyi, D. M., et al. (2017). "Consequences of animals crossing the edges of transfrontier parks," in Transfrontier Conservation Areas, eds J. A. Andersson, M. de Garine-Wichatitsky, D. H. M. Cumming, V. Dzingirai, and K. E. Giller (London: Routledge), 137-162.

Deutsch, C. A., Tewksbury, J. J., Tigchelaar, M., Battisti, D. S., Merrill, S. C., Huey, R. B., et al. (2018). Increase in crop losses to insect pests in a warming climate. Science 361, 916-919. doi: 10.1126/science.aat3466

Dively, G. P., Venugopal, P. D., Bean, D., Whalen, J., Holmstrom, K., Kuhar, T. P., et al. (2018). Regional pest suppression associated with widespread Bt maize adoption benefits vegetable growers. Proc. Nat. Acad. Sci. U.S.A. 115, 3320-3325. doi: 10.1073/pnas.1720692115

Dodd, W., Gomez Cerna, M., Orellana, P., Humphries, S., Sadoine, M. L., Zombré, D., et al. (2020). Factors associated with seasonal food insecurity among smallscale subsistence farming households in rural Honduras. Int. J. Environ. Res. Public Health. 17:706. doi: 10.3390/ijerph17030706

Findlay, L. J., and Hill, R. A. (2021). Baboon and vervet monkey crop-foraging behaviors on a commercial South African farm: preliminary implications for damage mitigation. Hum. Wildlife Interact. 14:19.

Food and Agricultural Organization (FAO) (2010). Global Food Security. Rome: Food and Agricultural Organization of the United Nations.

Food and Agricultural Organization (FAO) (2016). The State of Agricultural Commodity. Rome: Food and Agricultural Organization of the United Nations.

Gloriose, U. (2019). Community perceptions of human-wildlife conflicts and the compensation scheme around Nyungwe National Park (Rwanda). Int. J. Nat. Resource Ecol. Manage. 4, 188-197. doi: 10.11648/j.ijnrem.20190406.15

Guerbois, C., and Fritz, H. (2017). Patterns and perceived sustainability of provisioning ecosystem services on the edge of a protected area in times of crisis. Ecosyst. Serv. 28, 196-206. doi: 10.1016/j.ecoser.2017.11.010

Hill, C. M. (2000). Conflict of interest between people and baboons: crop raiding in Uganda. Int. J. Primatol. 21, 299-315. doi: 10.1023/A:1005481605637

Hill, C. M. (2018). Crop foraging, crop losses, and crop raiding. Annu. Rev. Anthropol. 47, 377-394. doi: 10.1146/annurev-anthro-102317-050022

Infield, M. (1988). Attitudes of a rural community towards conservation and a local conservation area in Natal, South Africa. Biol. Conserv. 45, 21-46. doi: 10.1016/0006-3207(88)90050-X

Infield, M. M. (1986). Wildlife resources, utilization and attitudes towards conservation: a case study of the Hluhluwe and Umfolozi Game Reserves in Natal/KwaZulu (MSc dissertation). University of Natal, Pietermaritzburg, South Africa.

Kaswamila, A., Russell, S., and McGibbon, M. (2007). Impacts of wildlife on household food security and income in northeastern Tanzania. Human Dimensions Wildlife 12, 391-404. doi: 10.1080/10871200701670003

Kiffner, C., Schaal, I., Cass, L., Peirce, K., Sussman, O., Grueser, A., et al. (2021). Perceptions and realities of elephant crop raiding and mitigation methods. Conserv. Sci. Prac. 3:e372. doi: 10.1111/csp 2.372

Koppmair, S., Kassie, M., and Qaim, M. (2017). Farm production, market access and dietary diversity in Malawi. Public Health Nutr. 20, 325-335. doi: $10.1017 / S 1368980016002135$

Long, H., Mojo, D., Fu, C., Wang, G., Kanga, E., Oduor, A. M., et al. (2020). Patterns of human-wildlife conflict and management implications in Kenya: a national perspective. Human Dimensions Wildlife 25, 121-135. doi: 10.1080/10871209.2019.169 5984

Lopez-Ridaura, S., Barba-Escoto, L., Reyna, C., Hellin, J., Gerard, B., and van Wijk, M. (2019). Food security and agriculture in the Western Highlands of Guatemala. Food Secur. 11, 817-833. doi: 10.1007/s12571-019-00940-z
Mackenzie, C. A., and Ahabyona, P. (2012). Elephants in the garden: financial and social costs of crop raiding. Ecol. Econ. 75, 72-82. doi: 10.1016/j.ecolecon.2011.12.018

MacKinnon, K., Smith, R., Dudley, N., Figgis, P., Hockings, M., Keenleyside, K., et al. (2020). "Strengthening the global system of protected areas post-2020: a perspective from the IUCN World Commission on Protected Areas," in Parks Stewardship Forum (Québec City, QC: eScholarship).

Mapiye, O., Chikwanha, O. C., Makombe, G., Dzama, K., and Mapiye, C. (2020). Livelihood, food and nutrition security in Southern Africa: what role do indigenous cattle genetic resources play?. Diversity 12:74. doi: $10.3390 / \mathrm{d} 12020074$

Matseketsa, G., Muboko, N., Gandiwa, E., Kombora, D. M., and Chibememe, G. (2019). An assessment of human-wildlife conflicts in local communities bordering the western part of Save Valley Conservancy, Zimbabwe. Global Ecol. Conserv. 20:e00737. doi: 10.1016/j.gecco.2019.e00737

Mugambiwa, S. S., and Tirivangasi, H. M. (2017). Climate change: a threat towards achieving 'Sustainable Development Goal number two'(end hunger, achieve food security and improved nutrition and promote sustainable agriculture) in South Africa. Jàmbá J. Disaster Risk Stud. 9, 1-6. doi: 10.4102/jamba. v9i1.350

Mukeka, J. M., Ogutu, J. O., Kanga, E., and Røskaft, E. (2019). Human-wildlife conflicts and their correlates in Narok County, Kenya. Global Ecol. Conserv. 18:e0620. doi: 10.1016/j.gecco.2019.e00620

Natukunda, S. (2019). Determinants and socio-economic impacts of crop raiding around bwindi impenetrable forest in Kayonza Sub County, Kanungu District (Doctoral dissertation). Makerere University, Kampala City, Uganda.

Nurdin, H., Hasanuddin, H., Darmawi, D., and Prasetya, F. (2018). "Analysis of calorific value of Tibarau cane briquette," in IOP Conference Series: Materials Science and Engineering (Lesvos: IOP Publishing).

Nyirenda, V. R., Nkhata, B. A., Tembo, O., and Siamundele, S. (2018). Elephant crop damage: subsistence farmers' social vulnerability, livelihood sustainability and elephant conservation. Sustainability 10:3572. doi: 10.3390/su101 03572

Okonya, J. S., Ocimati, W., Nduwayezu, A., Kantungeko, D., Niko, N., Blomme, G., et al. (2019). Farmer reported pest and disease impacts on root, tuber, and banana crops and livelihoods in Rwanda and Burundi. Sustainability 11:1592. doi: 10.3390/su11061592

Rahman, M., and Khan, T. I. (2019). "Issues beyond production and challenges ahead," in Regional Cooperation for Sustainable Food Security in South Asia, eds N. Kumar and J. George (Routledge: London).

Raphela, T. D. (2019). Crop raiding by wildlife on subsistence homesteads around the hluhluwe game reserve (Doctoral dissertation). Johannesburg, South Africa.

Schulze, K., Knights, K., Coad, L., Geldmann, J., Leverington, F., Eassom, A., et al. (2018). An assessment of threats to terrestrial protected areas. Conserv. Lett. 11:e12435. doi: 10.1111/conl.12435

Sekhar, N. U. (1998). Crop and livestock depredation caused by wild animals in protected areas: the case of Sariska Tiger Reserve, Rajasthan, India. Environ. Conserv. 25, 160-171. doi: 10.1017/S0376892998000204

Seoraj-Pillai, N., and Pillay, N. (2017). A meta-analysis of human-wildlife conflict: South African and global perspectives. Sustainability 9:34. doi: 10.3390/su9010034

Sibhatu, K. T., and Qaim, M. (2017). Rural food security, subsistence agriculture, and seasonality. PLoS ONE 12:e0186406. doi: 10.1371/journal.pone.0186406

Siljander, M., Kuronen, T., Johansson, T., Munyao, M. N., and Pellikka, P. K. (2020). Primates on the farm-spatial patterns of human-wildlife conflict in forest-agricultural landscape mosaic in Taita Hills, Kenya. Appl. Geogr. 117:102185. doi: 10.1016/j.apgeog.2020.102185

Silva, J. V., Baudron, F., Reidsma, P., and Giller, K. E. (2019). Is labour a major determinant of yield gaps in sub-Saharan Africa? A study of cerealbased production systems in Southern Ethiopia. Agric. Syst. 174, 39-51. doi: 10.1016/j.agsy.2019.04.009

Singh, R. K., Zander, K. K., Kumar, S., Singh, A., Sheoran, P., Kumar, A., et al. (2017). Perceptions of climate variability and livelihood adaptations relating to gender and wealth among the Adi community of the Eastern Indian Himalayas. Appl. Geogr. 86, 41-52. doi: 10.1016/j.apgeog.2017.06.018

Sinyolo, S. (2020). Technology adoption and household food security among rural households in South Africa: the role of improved maize varieties. Technol. Soc. 60:101214. doi: 10.1016/j.techsoc.2019.101214 
Siphesihle, Q., and Lelethu, M. (2020). Factors affecting subsistence farming in rural areas of nyandeni local municipality in the Eastern Cape Province. South Afr. J. Agric. Extens. 48, 92-105. doi: 10.17159/2413-3221/2020/v48n2a540

Smith, N. J., Williams, J. T., Plucknett, D. L., and Talbot, J. P. (2018). Tropical Forests and Their Crops. Ithaca, NY: Cornell University Press.

Statistics South Africa (2016). Formal Community Survey 2016. Pretoria: Statistics South Africa.

Vanhaute, E. (2011). From famine to food crisis: what history can teach us about local and global subsistence crises. J. Peasant Stud. 38, 47-65. doi: 10.1080/03066150.2010.538580

Wallach, A. D., Bekoff, M., Batavia, C., Nelson, M. P., and Ramp, D. (2018). Summoning compassion to address the challenges of conservation. Conserv. Biol. 32, 1255-1265. doi: 10.1111/cobi.13126

Wharton, C. R. (2017). "Subsistence agriculture: concepts and scope," in Subsistence Agriculture \& Economic Development (Routledge), 12-20.

World Health Organization (2020). The State of Food Security and Nutrition in the World 2020: Transforming Food Systems for Affordable Healthy Diets. Quebec City, QC.

Yan, S., Huang, D., and Soleymani, M. (2020). "Mitigating biases in multimodal personality assessment," in Proceedings of the 2020 International Conference on Multimodal Interaction (Utrecht), 361-369.

Yeheyes, Y., and Abebaw, G. (2017). "Effect of food insecurity shocks affecting households in Omo-Nada district southwestern Ethiopia," in DAAD Alumni Seminar (Addis Ababa), 45.
Zantsi, S., and Bester, B. (2019). Revisiting the benefits of animal traction to subsistence smallholder farmers: a case study of Ndabakazi Villages in Butterworth, Eastern Cape Province of South Africa. South Afr. J. Agric. Extension 47, 1-13. doi: 10.17159/2413-3221/2019/v47 $\mathrm{n} 3 \mathrm{a} 511$

Conflict of Interest: The authors declare that the research was conducted in the absence of any commercial or financial relationships that could be construed as a potential conflict of interest.

Publisher's Note: All claims expressed in this article are solely those of the authors and do not necessarily represent those of their affiliated organizations, or those of the publisher, the editors and the reviewers. Any product that may be evaluated in this article, or claim that may be made by its manufacturer, is not guaranteed or endorsed by the publisher.

Copyright $\odot 2021$ Raphela and Pillay. This is an open-access article distributed under the terms of the Creative Commons Attribution License (CC BY). The use, distribution or reproduction in other forums is permitted, provided the original author(s) and the copyright owner(s) are credited and that the original publication in this journal is cited, in accordance with accepted academic practice. No use, distribution or reproduction is permitted which does not comply with these terms. 